\title{
Self-reported health behaviour change in adults: analysis of the Canadian Community Health Survey 4.1
}

\author{
C. Haberman, MSc, RD (1); P. Brauer, PhD, RD (1); J. J. Dwyer, PhD (1); A. M. Edwards, PhD (2)
}

This article has been peer reviewed.

Tweet this article

\begin{abstract}
Introduction: Knowledge of Canadians' experiences in making health behaviour changes (HBCs) in general, and among those at risk due to body mass index (BMI), would help inform health promotion / disease prevention programs. Selected selfreported HBCs in the past 12 months by BMI category were examined in this secondary analysis of the Canadian Community Health Survey 4.1. These HBCs included increased sports/exercise, weight loss and improved eating habits. Barriers to HBC were also examined.
\end{abstract}

Methods: Descriptive analyses and forward stepwise logistic regression were completed on data from respondents 18 years and older. Self-reported BMI was corrected by the method of Connor Gorber et al. (2008).

Results: Our final sample was $n=111449$. Overall, $58 \%$ of respondents had made an HBC, with increased sports/exercise as the most important HBC in $29 \%$ of the sample, followed by improved eating habits (10\%) and weight loss (7\%). Half (51\%) experienced barriers to HBC; lack of will power was most commonly cited, followed by work and family responsibilities. Obese respondents reported HBC more frequently than normal-weight respondents ( $60 \%$ vs. $55 \%$ ), but the prevalence of increased sports/ exercise and improved eating habits was similar across BMI categories. Regression models accounted for only $6 \%-10 \%$ of the total variance.

Conclusion: That a majority of respondents had made at least one HBC bodes well for positively shifting population health. Additional work to further characterize the population, and to improve on population indicators, is needed to assess the impact of health promotion/disease prevention efforts. These findings provide important first population benchmarks for future work.

Keywords: health behaviour, obesity, weight loss, diet, physical activity, population characteristics

\section{Introduction}

With the development of the Canadian Community Health Survey (CCHS) in 2000 and the Canadian Health Measures Survey in 2009, health planners have improved their capacity to reliably assess the effects of health promotion / disease prevention efforts on the health of Canadians. ${ }^{1}$ Among many health issues, the rise in obesity is of particular interest as an intermediate risk factor for common chronic diseases.

Prevalence of overweight is currently $34.2 \%$ and of obesity is $26 \%$ among adults aged 18 to 79 years. $^{2}$ Diet and physical activity are primary lifestyle factors that influence obesity prevalence. To date, cross-sectional health surveys have provided limited infor- mation on the prevalence of physical activity and consumption of fruits and vegetables (as an indicator of a healthy diet). A review of the summary 2009-2012 CCHS tables shows that $56.2 \%$ of Canadians aged 12 years and older engage in enough leisure time activity to be considered at least moderately active ( $\geq 1.5 \mathrm{kcal} / \mathrm{kg} /$ day). ${ }^{2}$ Activity prevalence is stable; however, the percentage of Canadians consuming fruits and vegetables 5 or more times per day has decreased from $45.6 \%$ in 2009 to $40.6 \%$ in $2012 .^{3}$

Information on population prevalence of self-reported health behaviour change (HBC) to improve diet, physical activity and body weight-the main barriers to change-and the associated sociodemographic characteristics could both inform the development of new initiatives and provide population-based data to evaluate the longer-term success of public health approaches $^{4,5}$ An opportunity to examine the prevalence of HBC became available in the CCHS Cycle 4.1 (2007) along with information on associated demographic and health variables and barriers to change. ${ }^{6}$ The goals of this secondary analysis were to (1) examine the prevalence of self-reported HBC among adults in general and by body mass index (BMI) category, (2) determine the sociodemographic factors associated with $\mathrm{HBC}$ and (3) examine the prevalence of barriers to $\mathrm{HBC}$ by $\mathrm{BMI}$ category.

\section{Methods}

The CCHS Cycle 4.1 was a national, crosssectional survey of self-reported information on health status, health care utilization and health determinants including 
HBC. $^{6}$ Data were collected from respondents in all provinces and territories, and the results are representative of $98 \%$ of the Canadian population. Further details on the survey are available online. ${ }^{6}$

BMI was calculated and classified according to national standards for weight classification. ${ }^{7}$ The bias in self-reported BMI, where people underestimate their weight and overestimate their height, is well-recognized. $^{8} \quad$ Since self-reported height and weight were used in this study, we applied previously established correction equations to the BMI estimates of overweight and obese adults but not of normal-weight adults due to the smaller reporting bias in this group. ${ }^{9}$

This analysis was limited to non-pregnant respondents 18 years and older who responded themselves (not by proxy) and had a BMI between $18.5 \mathrm{~kg} / \mathrm{m}^{2}$ and $55.0 \mathrm{~kg} / \mathrm{m}^{2}$ prior to correction for selfreport bias. Respondents in the extreme ends of the BMI range were excluded as they face unique health challenges with respect to their body weight.
Self-reported HBC in the past year (Yes/ No) was the main outcome of interest. Respondents were also asked to identify the single most important HBC made in the past year (see Figure 1 for question flow pattern). Options for types of selfreported HBC included increased sports/ exercise, lost weight, improved eating habits, quit/reduced amount smoked, drank less alcohol, reduced stress level, received medical treatment, took vitamins, and undisclosed "other." If a respondent used multiple HBCs simultaneously, he or she had to select the single most important change.

Respondents who indicated they felt they should do something to improve their health were asked to identify barriers to $\mathrm{HBC}$ and allowed to select multiple barriers. Options for barriers to HBC included lack of willpower, work schedule, family responsibilities, disability, physical condition, too stressed, too costly, problems with the weather, addiction to drugs/ alcohol, not available in area, transportation problems and undisclosed "other." Willpower was the colloquial term used for perceived behavioural control, which is considered an overarching, superordinate construct, consisting of 2 lowerlevel components, self-efficacy and controllability. ${ }^{10,11}$

We ran descriptive statistics (using SPSS version 19.0 [IBM Corp., Armonk, NY, US]) to determine the demographic characteristics and prevalence of $\mathrm{HBC}$ among normalweight, overweight and obese respondents. When the chi-square indicated a difference in proportions, these were compared using a z-test (assuming central limit approximation applies) and adjusted for multiple comparisons using the Bonferroni adjustment. Continuous variables were examined by analysis of variance with posthoc comparison of means by Tamhane's T2, not assuming equal sample sizes or variances. Data were weighted using supplied sampling weights. $^{12}$ A subset analysis was then performed on respondents who did or did not undertake HBC and experienced barriers. Those who did not feel they needed to make additional HBCs (Figure 1) were excluded from this analysis.

FIGURE 1

Questionnaire flow diagram: health behaviour change module

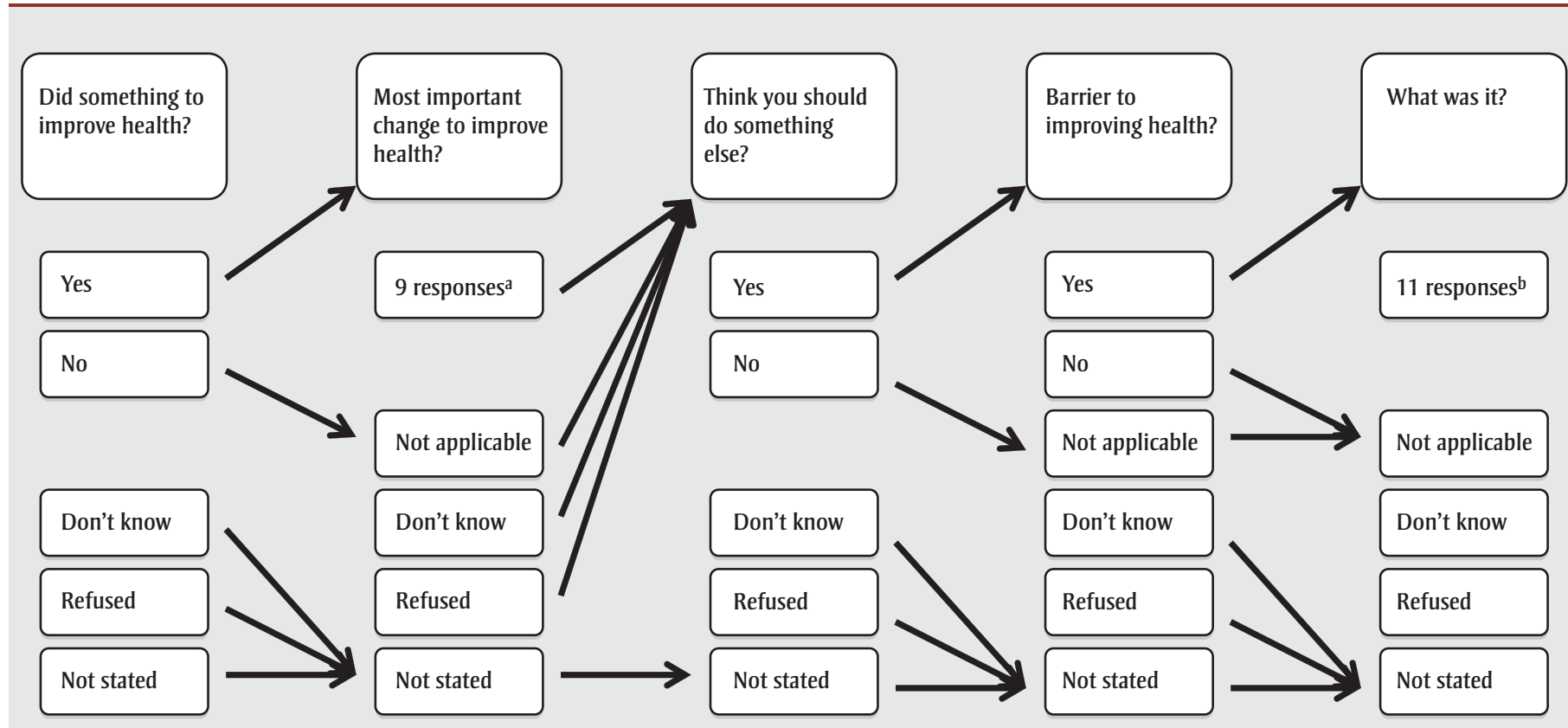

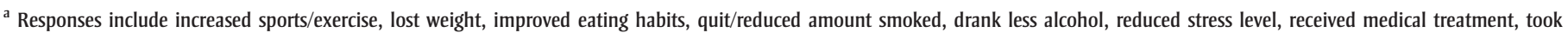
vitamins, and other.

${ }^{\mathrm{b}}$ Responses include lack of will power, work schedule, too costly, too stressed, disability, family responsibilities, addiction to drugs or alcohol, physical condition, not available in area, transportation problems, weather problems, and other.
} 
We used forward stepwise logistic regression to determine the variables associated with HBC in order of influence while controlling for age, sex, education and personal income. The initial regression models generated included all available variables in the CCHS that had been previously associated with weight change and physical activity in a preliminary literature review. The variables were age and sex, sociodemographic characteristics, education, income, immigration status, general health, self-reported height and weight, chronic conditions, medication use, changes made to improve health, food security, physical activity index, sedentary activity, social support and job stress. After reviewing for conceptual overlap, temporal issues and multicollinearity, we retained the most influential predictors. We created an initial regression model for HBC overall; based on those results, we then generated individual models predicting each specific HBC. Separate models were initially run for each BMI category; however, due to similarities between the models, all BMI categories were collapsed into a single grouping and BMI was included as a continuous predictor variable in the model. Model fit was assessed using Nagelkerke $R^{2}$ and the Hosmer-Lemeshow test. As the models explained little variance, no bootstrapping was conducted.

\section{Results}

Of the final sample ( $\mathrm{n}=111449$ ), $27 \%$ ( $n=30442$ ) of respondents were obese, $29 \%$ ( $\mathrm{n}=31831$ ) overweight and $44 \%$ ( $n=49$ 176) normal weight. See selected sociodemographic variables in Table 1.

Overall, 58\% ( $\mathrm{n}=64035)$ of respondents said they did something to improve their health (Table 2). Increased sports/exercise was the most popular HBC among all respondents ( $29 \%$; $n=31$ 936), followed by improved eating habits (10\%) and weight loss (7\%). All other HBC changes (13\%) included quit/reduced smoking, drank less alcohol, reduced stress level, received medical treatment, took vitamins, and other. A higher percentage of obese respondents $(60 \%)$ than normal-weight respondents $(55 \%)$ did something to improve their health.
Two-thirds (68\%; $\mathrm{n}=75717)$ of all respondents felt they should be doing more to improve their health. Of these, $51 \%$ ( $\mathrm{n}=38$ 193) met with one or more barriers to HBC (see Table 2), with lack of willpower the most commonly cited barrier $(34 \%)$, followed by work schedule (28\%) and family responsibilities (15\%). All other barriers were reported by less than $10 \%$ of respondents. Among those who experienced barriers to HBC, obese respondents were significantly more likely than normal-weight respondents to cite lack of willpower, disability or a physical condition as a barrier to health change ( $p<.05$ for all). Normal-weight respondents were significantly more likely than obese respondents to cite work, family responsibilities and cost as barriers to improving health ( $p<.05$ for all) (see Figure 2 ).

We performed a subset analysis to determine differences in the prevalence of barriers among those who did and did not report having made a HBC. Family responsibility was a statistically significantly greater barrier $(p<.001)$ among

TABLE 1

Basic demographic characteristics by BMI classification, $\geq 18$ years old, Canada, CCHS 2007

\begin{tabular}{|c|c|c|c|}
\hline Variable & $\begin{array}{c}\text { Obese } \\
\mathrm{n}=30442\end{array}$ & $\begin{array}{l}\text { Overweight } \\
\mathrm{n}=31831\end{array}$ & $\begin{array}{l}\text { Normal Weight } \\
n=49176\end{array}$ \\
\hline Male sex, ${ }^{a} \%$ & 53.5 & 61.0 & 43.3 \\
\hline Mean (SD) age, ${ }^{b}$ years & $48.7(15.6)$ & $48.5(16.4)$ & $43.7(17.6)$ \\
\hline Mean (SD) BMI, ${ }^{a} \mathrm{~kg} / \mathrm{m}^{2}$ & $34.3(4.4)$ & $27.9(1.1)$ & $22.4(1.7)$ \\
\hline Post-secondary graduate, ${ }^{a} \%$ & 55.5 & 59.9 & 60.8 \\
\hline Mean (SD) total personal income, ${ }^{\text {a }} \$$ & $\begin{array}{c}41904.9 \\
(40181.8)\end{array}$ & $\begin{array}{c}44135.8 \\
(43876.6)\end{array}$ & $\begin{array}{c}37176.5 \\
(37545.7)\end{array}$ \\
\hline Urban dwellers, ${ }^{\text {a }} \%$ & 78.2 & 80.7 & 84.3 \\
\hline Canada born, ${ }^{\text {a }} \%$ & 81.8 & 75.5 & 73.7 \\
\hline Aboriginal identity, ${ }^{\mathrm{c}} \%$ & 4.2 & 2.9 & 2.7 \\
\hline Caucasian, ${ }^{\text {a }} \%$ & 90.0 & 85.2 & 80.5 \\
\hline Never smoked, ${ }^{\mathrm{a}} \%$ & 32.5 & 34.6 & 38.6 \\
\hline Daily consumption of fruits and vegetables $<5 /$ day, ${ }^{\text {a }} \%$ & 61.0 & 57.9 & 54.3 \\
\hline Opinion of own weight: overweight, ${ }^{\mathrm{a}} \%$ & 86.6 & 53.3 & 14.4 \\
\hline Excellent or very good self-perceived general health, ${ }^{\mathrm{a}} \%$ & 45.1 & 59.9 & 65.6 \\
\hline $\begin{array}{l}\text { Mean (SD) number of consultations with medical } \\
\text { doctor in past year, }{ }^{c} n\end{array}$ & $4.6(7.5)$ & $3.7(6.9)$ & $3.5(6.1)$ \\
\hline
\end{tabular}

Abbreviations: BMI, body mass index; CCHS, Canadian Community Health Survey; SD, standard deviation.

${ }^{\text {a }}$ Each subset of BMI classification categories differ significantly from each other at the .05 level by z-test comparison of pairs of categories. Data are adjusted for multiple comparisons by Bonferroni adjustment.

${ }^{\mathrm{b}}$ Normal weight category differs significantly from other categories at the .05 level by z-test comparison of pairs of categories. Data are adjusted for multiple comparisons by Bonferroni adjustment.

c Obese weight category differs significantly from other categories at the .05 level by z-test comparison of pairs of categories. Data are adjusted for multiple comparisons by Bonferroni adjustment. those who did not make an HBC (16\%) than among those who did (15\%), but this difference was small. Cost was a significantly greater barrier $(p<.001)$ among those who made an HBC (6\%) than those who did not (4\%), but cost was not a prevalent barrier. Differences between $\mathrm{HBC}$ and non-HBC groups in the prevaence of barriers related to lack of willpower, work schedule, disability or

Initial logistic regression models showed that BMI, opinion of own weight, fruit and and self-perceived general health were all important variables associated with any HBC. A significant age by smoking status All models had limited power to account for model had a Nagelkerke $R^{2}$ of 0.07 , by the model; the Hosmer-Lemeshow test was significant at $p=.001$, indicating a poor model fit. The model for weight loss interaction effect was found for all models. the variance. The increased sports/exercise

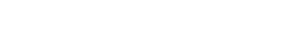


TABLE 2

Prevalence of health behaviour change characteristics by BMI, $\geq 18$ years old, Canada, CCHS 2007

\begin{tabular}{|c|c|c|c|c|}
\hline \multirow[t]{2}{*}{ Variable } & \multicolumn{4}{|c|}{ BMI classification } \\
\hline & $\begin{array}{c}\text { Obese } \\
\mathrm{n}=30442(\%)\end{array}$ & $\begin{array}{c}\text { Overweight } \\
\text { n = } 31831 \text { (\%) }\end{array}$ & $\begin{array}{l}\text { Normal weight } \\
\mathrm{n}=49176(\%)\end{array}$ & $\begin{array}{c}\text { Whole group } \\
\mathrm{n}=111449(\%)\end{array}$ \\
\hline \multicolumn{5}{|c|}{ Did something to improve health } \\
\hline Yes $^{\mathrm{a}}$ & $18314(60.2)$ & 18607 (58.5) & $27114(55.2)$ & $64035(57.5)$ \\
\hline $\mathrm{No}^{\mathrm{a}}$ & 12092 (39.8) & 13190 (41.5) & 22006 (44.8) & 47288 (42.5) \\
\hline Don't know/refused & 36 & 35 & 55 & 126 \\
\hline \multicolumn{5}{|l|}{ Most significant HBC } \\
\hline Not applicable ${ }^{\mathrm{a}}$ & 12092 (39.8) & $13190(41.5)$ & 22007 (44.9) & 47289 (42.5) \\
\hline Increased sports/exercise ${ }^{b}$ & $7898(26.0)$ & $9460(29.8)$ & 14578 (29.7) & $31936(28.7)$ \\
\hline Lost weight ${ }^{\mathrm{a}}$ & $3121(10.3)$ & $2315(7.3)$ & 1910 (3.9) & $7346(6.6)$ \\
\hline Improved eating habits ${ }^{\mathrm{a}}$ & 3156 (10.4) & $3087(9.7)$ & $4502(9.2)$ & $10745(9.7)$ \\
\hline Other $^{\mathrm{a}, \mathrm{c}}$ & $4113(13.5)$ & 3708 (11.7) & $6069(12.3)$ & $13890(12.5)$ \\
\hline Don't know/refused & 25 & 37 & 55 & 117 \\
\hline Not stated & 36 & 34 & 56 & 126 \\
\hline \multicolumn{5}{|c|}{ Thinks should do something else } \\
\hline Yes $^{\mathrm{a}}$ & $23405(77.5)$ & 21399 (67.7) & 30913 (63.2) & 75717 (68.4) \\
\hline $\mathrm{No}^{\mathrm{a}}$ & $6801(22.5)$ & $10227(23.3)$ & 17989 (36.8) & 35017 (31.6) \\
\hline Don’t know/refused & 201 & 172 & 219 & 589 \\
\hline Not stated & 36 & 34 & 56 & 126 \\
\hline \multicolumn{5}{|c|}{ Have barrier to improving health } \\
\hline Yes $^{\mathrm{a}}$ & $11885(50.9)$ & 10269 (48.1) & $16039(52.0)$ & 38193 (50.6) \\
\hline $\mathrm{No}^{\mathrm{a}}$ & 11452 (49.1) & 11079 (51.9) & $14790(48.0)$ & $37321(49.4)$ \\
\hline $\mathrm{N} / \mathrm{A}$ & 6801 & 10227 & 17989 & 35017 \\
\hline Don't know/refused & 67 & 51 & 84 & 201 \\
\hline Not stated & 236 & 206 & 274 & 717 \\
\hline
\end{tabular}

Abbreviations: BMI, body mass index; CCHS, Canadian Community Health Survey; HBC, health behaviour change.

${ }^{a}$ Each subset of BMI classification categories whose column proportions differed significantly from each other at the .05 level by z-test comparison of pairs of categories. Data are adjusted for multiple comparisons by Bonferroni adjustment.

b Obese category differed significantly from other categories at the .05 level by z-test comparison of pairs of categories. Data are adjusted for multiple comparisons by Bonferroni adjustment.

c Other includes: Quit smoking/reduced amount smoked, drank less alcohol, reduced stress level, received medical treatment, took vitamins and undisclosed other.

had a Nagelkerke $R^{2}$ of 0.10 , though the Hosmer-Lemeshow test was non-significant $(p=.12)$, indicating a good fit to the data. Similarly, the model for improved eating habits had a Nagelkerke $R^{2}$ of 0.06 , with a non-significant Hosmer-Lemeshow test $(p=.09)$.

Daily smoking was inversely associated with increased sports/exercise (odds ratio $[\mathrm{OR}]=0.66$; confidence interval $[\mathrm{CI}]=$ 0.63-0.70), while opinion of own weight status in the overweight range as well as of higher fruit and vegetable intake were positively associated with increased exercise (see Table 3). For the model for weight loss, opinion of own weight, BMI and increased fruits and vegetable intake were positively associated with weight loss, while smoking and self-perceived general health were not. Finally, for the model predicting improved eating habits, daily smoking was inversely associated, while opinion of weight, BMI and higher fruit and vegetable intake were also positively associated with improved eating habits, and no variables were excluded from the model.

\section{Discussion}

The fact that nearly $60 \%$ of adults reported making an $\mathrm{HBC}$ in the past 12 months was striking and suggests that many Canadians are both concerned about their health and willing to make positive changes. Similarly, the fact that two-thirds felt they should be doing more to improve their health suggests widespread concern. Since this was a new set of questions to be asked nationally (they had been asked in a subset in CCHS 3.1), it will be some years before comparative data will be available, either for longitudinal comparison or cross-sectionally with other surveys.

The focus on identifying the most important HBC was novel and provides new information, in contrast to other population studies that assessed a range of HBCs. ${ }^{13,14}$ Increased sports/exercise was reported nearly 3 times as often as the next most reported HBC of improved eating habits ( $29 \%$ vs. $10 \%$, respectively). This result runs counter to some other studies that have suggested that changes in physical activity may be more difficult than changes in diet among those who are overweight. $^{15}$

Variation among studies is considerable. Newson et al. ${ }^{16}$ looked at HBC after a chronic disease diagnosis in the National Population Health Survey cohort. Among the group who developed diabetes, who are generally advised by health care practitioners to both increase exercise and improve diet, ${ }^{17}$ the percentage who were physically active and consumed 5 or more servings of fruits and vegetables increased by $7 \%$; only 35 out of 487 adopted both behaviours. In contrast, among those who developed heart disease, the percentage meeting physical activity guidelines increased only $2 \%$ (from $51.6 \%$ to $53.9 \%$ ), compared with an increase of $9 \%$ (from $42 \%$ to $51 \%$ ) for meeting fruit and vegetable intake guidelines. Reasons for the differences are uncertain, but older subjects were less likely to make changes. ${ }^{16}$

Review of the exploratory logistic regression results in our study also hint at differences by health behaviour and health subgroups in the population. Various forms of cluster analysis could help further characterize groups in the population who are more likely to adopt different lifestyle changes. Overall, the high prevalence of 
FIGURE 2

Comparison of reasons for experiencing barriers to health behaviour change across BMI categories

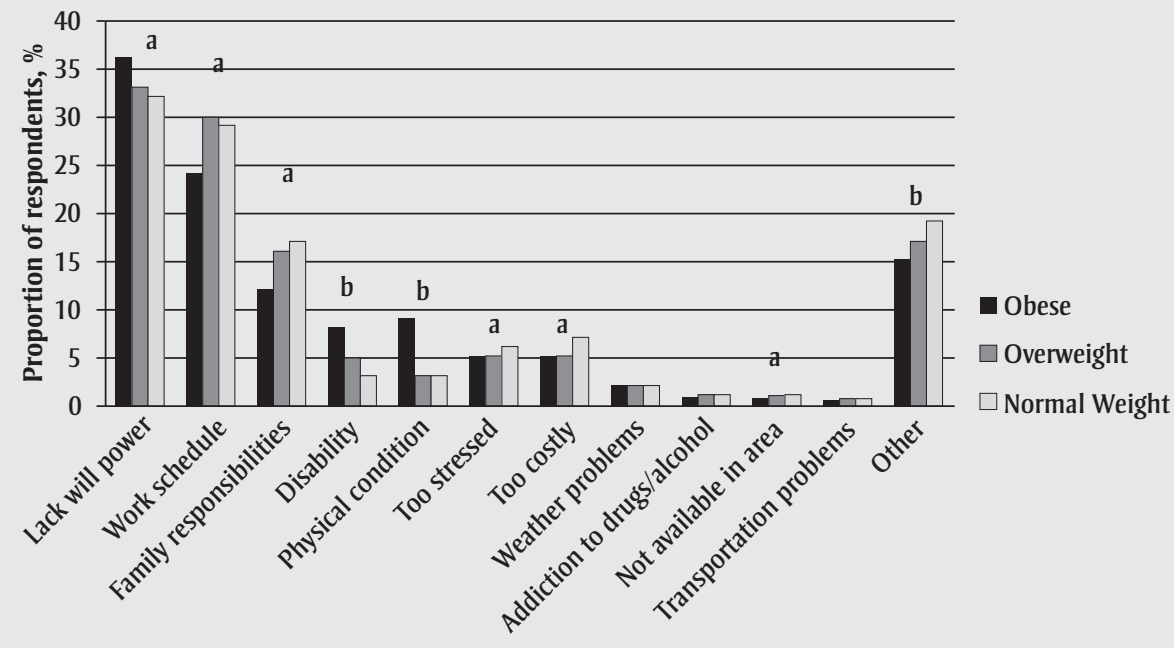

Barriers to $\mathrm{HBC}$

Abbreviations: BMI, body mass index; HBC, health behaviour change.

${ }^{\text {a }}$ Normal weight and obese BMI groups differ significantly at $p<.05$.

${ }^{\mathrm{b}}$ All BMI groups differ significantly at $p<.05$.

self-reported increased exercise was encouraging.

An a priori focus of this work was to assess the overall prevalence of the main $\mathrm{HBC}$ associated with body weight management (diet, exercise, weight loss), comparing respondents categorized by BMI levels that have been previously established for their relationship to mortality risk (normal, overweight and obese). It was notable that weight loss as the primary $\mathrm{HBC}$ was relatively rare ( $10 \%$ of obese respondents), in line with a large body of evidence showing that weight loss is challenging. Such population-based data are important because the majority of weight loss attempts occur outside of the health care system and are not tracked in any way. While no details were asked of CCHS respondents, in a study using data from the National Health and Nutrition Examination Survey (NHANES) 1999-2004 and limited to respondents with central obesity and cardiovascular disease, $15 \%$ reported losing $5 \%$ or more of body weight. ${ }^{18}$ A much higher percentage (38\%) of obese respondents who completed an inperson interview during the 2001-2006 NHANES reported losing $5 \%$ or more of body weight. $^{19}$ Similarly, $35 \%$ of obese lically fit obese have decreased mortality risk of cardiovascular disease compared with the unfit. ${ }^{21,22}$

Assessment of prevalence of barriers was unique to the CCHS; other large surveys assessing similar concepts were not found. Half of the relevant respondents did not report any barriers to HBC. Among those who did report barriers, lack of willpower (as expected) was the most commonly cited, followed by work schedule and family responsibilities.

Willpower includes the concepts of selfefficacy and controllability, key foci of much of the health behaviour literature, as evidenced by such seminal texts as Health Behavior and Health Education, first published in 1990, which provided the first overview of all the major theories at that time. ${ }^{23}$ Since then, the importance of environmental and social context in affecting individual behaviour has been increasingly recognized. Lack of time is one such barrier to HBC commonly cited in the literature. $^{24,25,26}$ Lack of time was not listed as an option in the CCHS; however, as work and family responsibilities are time-intensive tasks that reduce the time available to undertake $\mathrm{HBC}$, it may be inferred that these tasks describe similar barriers. Considering overall barriers by BMI, obese respondents reported a similar prevalence of barriers as normal-weight respondents ( $51 \%$ vs. $52 \%$ ), but the types of barriers differed somewhat, with disability and lack of willpower being more common but work and family responsibilities being less common among obese respondents. Overall, however, transportation, cost, stress and lack of availability were not endorsed as common barriers by the majority of Canadians. Such population-based data on prevalence of key barriers to $\mathrm{HBC}$ has implications for the design of new approaches.

Our logistic regression modelling was exploratory and aimed at identifying possible associations beyond the obvious differences by age, gender, income and education. The association between BMI and $\mathrm{HBC}$ has been previously observed: Verheijden et al. ${ }^{27}$ found that obese respondents were more likely than normal-weight respondents to continue to 
TABLE 3

Summary of health behaviour change regression models, $\geq 18$ years old, Canada, CCHS 2007

\begin{tabular}{|c|c|c|c|c|c|c|}
\hline & \multicolumn{2}{|c|}{ Increased sports/exercise } & \multicolumn{2}{|c|}{ Lost weight } & \multicolumn{2}{|c|}{ Improved eating habits } \\
\hline & OR & $95 \% \mathrm{Cl}$ & OR & $95 \% \mathrm{Cl}$ & OR & $95 \% \mathrm{Cl}$ \\
\hline BMI (per unit increase) & - & - & 1.06 & $1.05-1.07$ & 1.02 & $1.01-1.02$ \\
\hline \multicolumn{7}{|l|}{ Smoking status } \\
\hline Never $^{\mathrm{a}}$ & - & - & - & - & - & - \\
\hline Daily & 0.66 & $0.63-0.70$ & - & - & 0.72 & $0.66-0.77$ \\
\hline Occasional (former daily) & 1.04 & $0.94-1.16$ & - & - & 0.99 & $0.85-1.16$ \\
\hline Always occasional & 1.18 & $1.04-1.34$ & - & - & 0.88 & $0.72-1.08$ \\
\hline Former daily & 1.13 & $1.08-1.19$ & - & - & 1.14 & $1.06-1.22$ \\
\hline Former occasional & 1.08 & $1.02-1.14$ & - & - & 1.22 & $1.13-1.32$ \\
\hline \multicolumn{7}{|l|}{ Opinion of own weight ${ }^{b}$} \\
\hline About right ${ }^{\mathrm{a}}$ & - & - & - & - & - & - \\
\hline Overweight & 1.27 & $1.23-1.32$ & 1.79 & $1.66-1.94$ & 1.26 & $1.18-1.34$ \\
\hline Underweight & 1.04 & $0.94-1.15$ & 0.93 & $0.73-1.19$ & 0.90 & $0.77-1.06$ \\
\hline \multicolumn{7}{|l|}{ Fruit and vegetable intake ${ }^{c}$} \\
\hline$<5$ times $/$ day $^{\mathrm{a}}$ & - & - & - & - & - & - \\
\hline 5-10/day & 1.28 & $1.23-1.33$ & 1.42 & $1.33-1.52$ & 1.45 & $1.37-1.53$ \\
\hline$>10$ times/day & 1.33 & $1.22-1.45$ & 1.55 & $1.34-1.81$ & 1.86 & $1.65-2.08$ \\
\hline \multicolumn{7}{|c|}{ Number of consultations with doctor ${ }^{\mathrm{d}}$} \\
\hline & 1.01 & $1.01-1.01$ & 1.02 & $1.02-1.02$ & 1.01 & $1.01-1.02$ \\
\hline \multicolumn{7}{|l|}{ Self-perceived general health ${ }^{\mathrm{e}}$} \\
\hline Excellent $^{\mathrm{a}}$ & - & - & - & - & - & - \\
\hline Poor/Fair & 1.01 & $0.94-1.09$ & - & - & 1.52 & $1.36-1.69$ \\
\hline Good & 1.12 & $1.06-1.18$ & - & - & 1.45 & $1.34-1.57$ \\
\hline Very Good & 1.17 & $1.12-1.23$ & - & - & 1.37 & $1.27-1.47$ \\
\hline
\end{tabular}

Abbreviations: BMI, body mass index; CCHS, Canadian Community Health Survey; $\mathrm{Cl}$, confidence interval; HBC, health behaviour change; OR, odds ratio.

${ }^{\text {a }}$ Referent category.

b This variable classifies the respondent by their self-reported opinion of their own weight.

c This variable classifies the respondent by the total number of times per day he/she eats fruits and vegetables, based on a food frequency recall.

d This variable indicates the number of times respondents have seen or talked to a family doctor or specialist in the last 12 months.

e This variable indicates the respondent's health status based on his/her own judgement.

participate in an HBC-promotion program, while Teixeria et al. ${ }^{28}$ found a positive correlation between BMI and weight loss.

Smoking has often been inversely associated with $\mathrm{HBC}^{27,29,30}$ Higher fruit and vegetable intake has been consistently associated with better health in many epidemiological studies, so it was not surprising that people who already ate more fruits and vegetables were also more likely to make HBCs. Perception of overweight status and general health, as well as greater number of consultations with physicians were all associated with undertaking $\mathrm{HBC}$, as observed in previous studies. $^{31}$ Better characterization of the subgroups who undertake HBC is needed to guide health promotion efforts. Each of these variables should be considered in more detail; they may be indirect indicators of lifestyle or other factors, which may in turn be associated with HBC. Further research is required to fully understand these relationships.

Only one previous study has examined HBC in the CCHS 4.1; Hystad and Carpiano's ${ }^{32}$ results for overall prevalence of HBC confirmed ours. Sense of belonging in the community was the focus of their work. In our analysis, sense of belonging was included as a possible predictor in the initial regression models. Though statistically significant, sense of belonging in the community was strongly overshadowed by other variables and accounted for very little unique variance in the model. As a result, we removed it from the final model for the sake of parsimony.

\section{Strengths and limitations}

Strengths of this study include (1) a baseline estimate of the prevalence of the most important HBC activities and (2) the barriers to change by BMI category at the population level in Canada. Over time, it will be possible to better assess outcomes of health promotion efforts at the population level.

There are also significant limitations. While the HBC measures in the CCHS 4.1 provided important new information, we could not find published assessments of reliability or of the various types of validity of the questions in Statistics Canada documentation or in peerreviewed literature. It was stated that expert advice was sought on measures; ${ }^{12}$ thus, the current measures are a starting point. However, the conceptualization of losing weight versus exercise versus diet change as separate HBCs need more development and validation for population surveys because changes to improve both diet and physical activity are typically required to change body weight. Such work is urgently needed since surveillance of population HBC would be a potentially valuable addition to current tools used for assessing HBC. The relative merits of reporting on the most important $\mathrm{HBC}$, as done in this study, versus multiple concurrent HBCs is also unknown. Similarly, further work is needed to assess the reliability and validity of self-reports of barriers to change.

Categorization of obesity status by BMI was another limitation of this and other population health surveys as it has become increasingly clear that BMI alone may be an inadequate indicator of health or mortality risk. Various strategies will be needed to address this issue, including more subsample approaches. ${ }^{19,20}$ 


\section{Conclusion}

This analysis of self-reported HBCs and barriers in the CCHS 4.1 revealed a high prevalence of $\mathrm{HBC}$ overall, and especially of increased exercise by a substantial minority of adults. While we were particularly interested in possible differences by obesity status, this analysis indicated the obese are very similar to the normal weight in reported HBCs. The regression analyses also identified other factors that may help further characterize the population. Further methodological development of the methods for assessing HBCs and barriers in the population are needed, but the current study has provided new information that can inform development of future HBC strategies.

\section{References}

1. Health Council of Canada. Stepping it up: moving the focus from health care in Canada to a healthier Canada. Toronto (ON): Health Council of Canada; 2010.

2. Statistics Canada. Canadian Health Measures Survey: Cycle 2 Data Tables 2009 to 2011. Ottawa (ON): Government of Canada; 2012.

3. Statistics Canada summary tables: tables by subject [Internet]. Ottawa (ON): Government of Canada; [cited 2013 Oct 3]. Available from: http://www.statcan.gc.ca/tables-tableaux /sum-som/101/ind01/13_2966_2968-eng .htm?hili_health77

4. Plotnikoff RC, Lippke S, Johnson ST, Hugo K, Rodgers W, Spence JC. Awareness of Canada's Physical Activity Guide to Healthy Active Living in a large community sample. Am J Health Promot. 2011;25:294-7.

5. Garcia AC, Piche LA. Perceptions and use of Canada's Food Guide to Healthy Eating by grocery shoppers in London, Ontario. Can J Diet Pract Res. 2001;62:123-7.

6. Statistics Canada. Canadian Community Health Survey - Annual Component (CCHS). Detailed information for 2007 (Cycle 4.1) [Internet]. Ottawa (ON): Government of Canada; [modified 2008 Jun 17; cited 2013 Oct 3]. Available from: http://www23 .statcan.gc.ca/imdb/p2SV.pl?Function = get Survey\&SurvId $=50653 \&$ InstaId $=29539 \&$ SDDS $=3226$
7. Health Canada. Canadian guidelines for body weight classification in adults. Ottawa (ON): Health Canada Publications Centre; 2003.

8. Gorber SC, Tremblay MS. The bias in selfreported obesity from 1976 to 2005: a Canada-US comparison. Obesity. 2010;18(2): 354-61.

9. Gorber SC, Shields M, Tremblay MS, McDowell I. The feasibility of establishing correction factors to adjust self-reported estimates of obesity. Health Rep. 2008;19(3): 71-82.

10. Ajzen I. Perceived behavioral control, selfefficacy, locus of control, and the theory of planned behavior. J Appl Social Psychol. 2002;32(4):665-83.

11. Strecher VJ, DeVellis BM, Becker MH, Rosenstock IM. The role of self-efficacy in achieving health behavior change. Health Educ Q. 1986;13(1):73-92.

12. Statistics Canada. Canadian Community Health Survey (CCHS). 2007 Microdata Files User Guide; June 2008 Ottawa (ON): Government of Canada; [cited 2013 Oct 3]. Available from: http://www23.statcan.gc .ca/imdb-bmdi/document/3226_D7_T9_V4 -eng.pdf

13. Prochaska JJ, Spring B, Nigg CR. Multiple health behavior change research: an introduction and overview. Prev Med. 2008;46(3): 181-8.

14. Lippke S, Nigg CR, Maddock JE. Healthpromoting and health-risk behaviors: theory-driven analyses of multiple health behavior change in three international samples. Int J Behav Med. 2012;19(1):1-13.

15. Bish CL, Blanck HM, Maynard LM, Serdula MK, Thompson NJ, Khan LK. Activity/ participation limitation and weight loss among overweight and obese US adults: 1999 to 2002 NHANES. MedGenMed. 2007; 9(3):63.

16. Newson JT, Huguet N, Ramage-Morin PL, et al. Health behaviour changes after diagnosis of chronic illness among Canadians aged 50 or older. Health Rep. 2012;23(4):4953.
17. Canadian Diabetes Association Clinical Practice Guidelines Expert Committee. Canadian Diabetes Association 2013 Clinical Practice Guidelines for the Prevention and Management of Diabetes in Canada. Can J Diabetes. 2013;37(suppl 1):S1-S212.

18. Singh S, Somers VK, Clark MM, et al. Physician diagnosis of overweight status predicts attempted and successful weight loss in patients with cardiovascular disease and central obesity. Am Heart J. 2010;160(5): 934-42.

19. Nicklas JM, Huskey KW, Davis RB, Wee CC. Successful weight loss among obese U.S. adults. Am J Prev Med. 2012;42(5):481-5.

20. Counterweight Project Team. The implementation of the Counterweight Programme in Scotland, UK. Fam Pract. 2012; 29(Suppl 1):i139-44.

21. Hamer M, Stamatakis E. Metabolically healthy obesity and risk of all-cause and cardiovascular disease mortality. J Clin Endocrinol Metab. 2012;97(7):2482-8.

22. Ortega FB, Lee DC, Katzmarzyk PT, et al. The intriguing metabolically healthy but obese phenotype: cardiovascular prognosis and role of fitness. Eur Heart J. 2013;34(5): 389-97.

23. Glanz K, Lewis FM, Rimer BK, editors. Health behavior and health education: theory, research and practice. San Francisco (CA): Jossey-Bass; 1990.

24. Ruelaz AR, Diefenbach P, Simon B, Lanto A, Arterburn D, Shekelle PG. Perceived barriers to weight management in primary care--perspectives of patients and providers. J Gen Intern Med. 2007;22(4):518-22.

25. Mauro M, Taylor V, Wharton S, Sharma AM. Barriers to obesity treatment. Eur J Intern Med. 2008;19(3):173-80.

26. Welch N, McNaughton SA, Hunter W, Hume C, Crawford D. Is the perception of time pressure a barrier to healthy eating and physical activity among women? Public Health Nutr. 2009;12(7):888-95.

27. Verheijden MW, Jans MP, Hildebrandt VH, Hopman-Rock M. Rates and determinants of repeated participation in a web-based behavior change program for healthy body weight and healthy lifestyle. J Med Internet Res. 2007;9(1):e1. 
28. Teixeria PJ, Going SB, Sardinha LB, Lohman TG. A review of psychosocial pre-treatment predictors of weight control. Obesity Rev. 2005;6(1):43-65.

29. Van Horn L, Dolecek TA, Grandits GA, Skweres L. Adherence to dietary recommendations in the special intervention group in the Multiple Risk Factor Intervention Trial. Am J Clin Nutr. 1997;65(1 Suppl):289S$304 S$.

30. Stubbs J, Whybrow S, Teixeira P, et al. Problems in identifying predictors and correlates of weight loss and maintenance: implications for weight control therapies based on behaviour change. Obes Rev. 2011;12(9):688-708.

31. Yaemsiri S, Slining MM, Agarwal SK. Perceived weight status, overweight diagnosis, and weight control among US adults: The NHANES 2003-2008 study. Int J Obes. 2011;35(8):1063-70.

32. Hystad P, Carpiano RM. Sense of community-belonging and health-behaviour change in Canada. J Epidemiol Community Health. 2012;66(3):277-83. 